\title{
Embriaguez ao volante: como provar o fato em juízo e evitar a impunidade?
}

\section{Driving under influence of alcohol: how to prove the fact in judment and avoid the impunity?}

\author{
Cássio M. Honorato(1)
}

Honorato CM. Embriaguez ao volante: como provar o fato em juízo e evitar a impunidade? Saúde, Ética \& Justiça, São Paulo. 2003;8(1/2):35-43.

\begin{abstract}
RESUMO: O presente estudo destaca alguns aspectos técnicos e científicos relacionados ao crime de embriaguez ao volante (descrito no artigo 306, do Código de Trânsito Brasileiro), enfatizando os meios de prova em direito admitidos e a reconhecida importância do exame clínico e da prova testemunhal perante a Justiça brasileira.
\end{abstract}

DESCRITORES: Intoxicação alcoólica. Consumo de bebidas alcoólicas/legislação \& jurisprudência. Acidentes de trânsito.

\section{INTRODUÇÃO}

Sabe-se que o fenômeno trânsito é representado graficamente como um triângulo, contendo em cada um de seus vértices um "E". São os conhecidos "3E", ou seja, "EDUCAÇÃO", "ENGENHARIA" e "ENFORCEMENT"; sendo este último um conjunto de esforços legais, judiciais e policiais voltados à realização do trânsito em condições seguras (art. 1을 $\S 2^{\circ}$, CTB).

Para atingir tal objetivo não basta a publicação de um novo Código, a produção de veículos mais seguros, a construção de novas rodovias, ou o aumento do efetivo dos diferentes órgãos de fiscalização de trânsito. Faz-se necessária a implantação de uma nova filosofia, ou melhor, de um novo meio de encarar o trânsito.

Exemplos simples (e eficazes) podem ser encontrados na legislação do Estado de Nova York, que já foi sede de uma das cidades mais violentas e atualmente encontra-se sob "Lei de Tolerância Zero". Dois fatores, particularmente, chamaram nossa atenção:

\footnotetext{
(1) Promotor de Justiça no Estado do Paraná. Especialista em Trânsito pela Polícia Rodoviária do Estado de São Paulo. Mestre em Direito pela Universidade Estadual do Paraná - UNESPAR - campus Jacarezinho. Professor de Direito Constitucional da Faculdade Novo Ateneu de Guarapuava.

Endereço para correspondência: Rua Capitão Virmond, 1913. Centro - Guarapuava, Paraná. CEP 85010-120. e-mail: cmhonorato@pr.gov.br
} 
O fato de as primeiras páginas do "Manual de Direção" conterem mensagens (acompanhadas das assinaturas e das fotografias) do Governador do Estado e do Comissário do Departamento de Veículos Automotores; trazendo credibilidade e seriedade ao texto dirigido aos usuários das vias terrestres.

Destaca-se, ao final da exposição do Comissário a seguinte mensagem [traduzida livremente]: "o trânsito seguro é responsabilidade de todos. A saúde e as vidas sua, de sua família, amigos e dos demais usuários das vias podem depender de como você aprendeu e usou as informações desse Manual. Esperamos que você desfrute de muitos anos de direção segura" (p.2.) $)^{14}$.

O segundo fato, diretamente relacionado ao trânsito em condições seguras, consiste na substituição da expressão "acidente de trânsito" (i.e., "accident") por "crash". Não se trata de simples mudança de rótulo - retirando accident e introduzindo crash-, e sim remover a falsa noção de fatalidade que recai sobre os eventos que causam milhares de mortes e lesões no trânsito; atribuindo-se à conduta humana que gerou o evento juridicamente relevante o devido grau de responsabilidade.

No Brasil, o conceito de acidente de trânsito encontra-se previsto na NBR n. 10697, de junho de 1989; intocado, ainda sem substituto (por enquanto!):

"3.1.1 Acidente de Trânsito: Todo evento não premeditado de que resulte dano em veículo ou na carga e/ou lesões em pessoas e/ou animais, em que pelo menos uma das partes está em movimento nas vias terrestres ou áreas abertas ao público. Pode originar-se, terminar ou envolver veículo parcialmente na via pública".

Veja-se que em 1997 foi publicado um novo Código de Trânsito, em verdade é o $4^{\circ}$ Código Nacional de Trânsito. No entanto, de nada valem novos dispositivos se os operadores do Direito, os continuarem lendo com as velhas lentes; poucos resultados práticos surgirão, se os usuários das vias terrestres mantiverem as mesmas atitudes imprudentes no trânsito; e os agentes de fiscalização não perceberem seu real papel na concretização do trânsito em condições seguras.

De nada valem os " $3 \mathrm{E}$ " se estiverem divorciados, desunidos, sem rumo. Esses três elementos não podem ser considerados de forma linear, plana ou superficial; torna-se indispensável associar a cada um desses vértices um quarto elemento, denominado ciência. Assim, a partir de uma figura plana chegaríamos a uma pirâmide, em que seria exigido o devido tratamento científico a cada um dos elementos que compõem a base dessa pirâmide.

Teríamos, assim, a ciência (i) colocada a serviço da engenharia de tráfego, (ii) a aprimorar as atividades dos órgãos e entidades que compõem o Sistema Nacional de Trânsito, (iii) a levar o trânsito para dentro das salas de aulas, e (iv) conformar o exercício do poder punitivo do Estado aos princípios expressamente previstos na Constituição brasileira.

Trânsito, portanto, é fenômeno complexo, multidiciplinar, que também precisa ser visto como ciência.

\section{Crime de trânsito, cidadania, segurança e fiscalização - impunidade}

Inicialmente, destacando os tópicos "Segurança e Fiscalização", restou sustentado que "Em regra, todo [desculpem a expressão, porém é o termo técnico previsto na legislação de trânsito brasileira] acidente de trânsito é precedido e decorre, direta ou indiretamente, de uma infração de trânsito" (p.351) ${ }^{10}$.

Abreu $^{1}$, com arrimo na exposição de Ferrari ${ }^{6}$, que trata do Princípio do Respeito à Corrente do Trânsito, vai ainda além da referida tese, ao sustentar que "manobra perturbativa lícita é suspeita, ilícita é culpável". Destaca-se a lição do autor:

Não chega a ser um direito concedido a alguém, mas é incontestável esta prioridade em favor dos que circulam no sentido da corrente da linha diretriz da pista e sem mudanças bruscas de velocidade. Todas as demais ações no trânsito se consideram por isso perturbadoras, algumas embora perfeitamente legais e necessárias à movimentação dos veículos. Porém, devem ser empreendidas na devida oportunidade e estritamente conforme as regras de trânsito, que as cercam de cautelas extras. Segundo Ferrari ${ }^{6}$, "no que concerne à responsabilidade dos protagonistas dos sinistros rodoviários, deveria valer (em uma racional e simples regra do tráfego) o princípio: manobra turbativa lícita é suspeita, ilícita é culpável. Nos sinistros, com o concurso de várias pessoas, há sempre à origem do evento e como causa principal deles a ação de um perturbador, que exorbita da regra do jogo do tráfego" (p.186-7). Ainda no mesmo sentido, em França, é o raciocínio de Toché20 (p.54): "os acidentes 
devidos à perturbação, legal ou ilegal, têm este caráter indiscutível: o perturbador é sempre o autor, então, insistamos ainda neste ponto, deve ser quem paga" (p.159) ${ }^{1}$.

Encontra-se, aliás, expressamente prevista na Ley de Tránsito Argentina, em seu artigo 64, presunção de culpa daquele que cometer uma infração de trânsito relacionada com a causa do evento: "Se presume responsable de un accidente al que carecía de prioridad de paso o cometió una infracción relacionada con la causa del mismo [...]" (p.CVII) ${ }^{17}$.

Extrai-se dessas teses e presunções legais a relevância da atividade de fiscalização e de policiamento de trânsito, como fatores de prevenção de acidentes de trânsito, sempre voltados ao atingm ento do objitivo pribritáriodescrito no artigo 269, § 1ํ, do CTB: "A ordem, o consentimento, a fiscalização, as medidas administrativas e coercitivas adotadas pelas autoridades de trânsito e seus agentes terão por objetivo prioritário a proteção à vida e à incolumidade física da pessoa".

Especificamente relacionado aos tópicos "Cidadania e Impunidade", fez-se necessário destacar, dentre os "Crimes de Trânsito propriamente ditos", o Crime de Embriaguez ao Volante (descrito junto ao art. 306, do CTB):

Art. 306. Conduzir veículo automotor, na via pública, sob a influência de álcool ou substância de efeitos análogos, expondo a dano potencial a incolumidade de outrem:

Penas - detenção, de seis meses a três anos, multa e suspensão ou proibição de se obter a permissão ou a habilitação para dirigir veículo automotor.

Dentre os fundamentos a justificar a opção pelo tema, puderam ser destacados os seguintes aspectos:

$1^{\circ}$. Por ser um dos mais complexos, controvertidos e menos estudados crimes de trânsito, sob a lente da moderna ciência jurídica;

$2^{\circ}$. Por que "O alcoolismo é um dos maiores problemas de saúde pública do mundo": "o País gasta $7,3 \%$ do Produto Interno Bruto (PIB) por ano para tratar de problemas relacionados ao álcool"; "mais de $90 \%$ das internações hospitalares"; e "além de aparecer em cerca de $70 \%$ dos laudos cadavéricos das mortes violentas"15.

$3^{\circ}$. Por que se verifica, ainda muito presente no Brasil, "uma tolerância social muito grande em rela- ção ao ato de beber e dirigir"'11. Curiosamente a palavra "whisky" (do gálico "usquebaugh") significa "água da vida", e na Idade Média foi "considerado como um remédio para aliviar os males, pois dissipava as preocupações mais rapidamente do que o vinho e a cerveja, produzindo um alívio mais eficiente contra a dor"15. E hoje é responsável direto por grande parcela dos acidentes de trânsito.

Segundo o National Highway Traffic Safety Administratin (NHTSA), em 1996 foram constatadas 17.126 mortes no trânsito relacionadas ao uso do álcool, representando uma fatalidade a cada $31 \mathrm{mi}-$ nutos. No Brasil, poucos são os estudos mais abrangentes em que se aferem, objetivamente, o uso do álcool em acidentados do trânsito, mas sabe-se que o número de mortos é tão grande ou até maior que aquele representado pelo $\mathrm{NHTSA}^{4}$.

$4^{\circ}$. Ainda mais importante é o fato constatado em pesquisa de Leyton e Greve ${ }^{11}$, da USP, que revelou três importantes conclusões: (i) "uso de bebidas alcoólicas contribuiu para quase metade das mortes por acidente de trânsito nas amostra estudada"; (ii) "as mortes por acidente de trânsito no sexo masculino estão mais relacionadas com o uso do álcool que no sexo feminino"; (iii) "os valores médios de alcoolemia encontrados foram aproximadamente três vezes superiores ao estabelecido pelo Código de Trânsito Brasileiro [...], indicando que a maioria das vítimas alcoolizadas fez uso excessivo de bebida alcoólica"4. Há, portanto, "uma evidente relação entre o uso de álcool e a presença de vítimas fatais em acidentes de trânsito"4.

Acredita-se, portanto, que somente através de informação e educação pode-se reverter este quadro, e proporcionar o trânsito em condições seguras para as futuras gerações.

Justificada a opção pelo tema, passa-se a discorrer sobre a Embriaguez ao Volante, em especial sobre a fiscalização e os meios de prova a serem produzidos.

Os aspectos controvertidos são muitos. Apenas para citar alguns, destacam-se: (i) a aplicabilidade, ou não, dos institutos descritos no art. 291, par. ún., do CTB (i.e., composição civil, transação penal e representação criminal); (ii) a questão da caracterização do tipo penal de injusto (i.e., norma penal em branco, crime de perigo concreto, 
crime de mera conduta); (iii) o que se entende por "substâncias de efeitos análogos" ao álcool?

Hoje, no entanto, tentaremos nos concentrar sobre um único ponto; altamente questionado, porém pouco levado a sério: como provar que determinada pessoa encontrava-se conduzindo veículo automotor, em via pública, sob a influência de álcool [...]? Ou seja: embriaguez ao volante: como provar o fato em juízo e evitar a impunidade?

Em Portugal a legislação é específica ${ }^{[1]}$, e relaciona os seguintes "métodos de fiscalização": (i) teste no ar expirado, efectuado em analisador qualitativo; (ii) teste em analisador quantitativo; (iii) análise de sangue, realizado em serviço de urgência hospitalar mais próximo; (iv) exame toxicológico de sangue, realizado pelos istitutos de medicina legal; (v) exame médico (p.491-6) ${ }^{3}$.

No Brasil, o Código de Processo Penal enumera no Título que trata "Da Prova" os seguintes meios de prova: (i) perícias, (ii) interrogatório do acusado, (iii) testemunhas; (iv) documentos. Especificamente em relação ao Fenômeno Trânsito, o art. 277 do CTB relaciona, de forma alternativa (i.e., empregando a expressão "ou"), os seguintes "meios de prova":

Art. 277. Todo condutor de veículo automotor, envolvido em acidente de trânsito ou que for alvo de fiscalização de trânsito, sob suspeita de haver excedido os limites previstos no artigo anterior, será submetido a testes de alcoolemia, exames clínicos, perícia, ou outro exame que por meios técnicos ou científicos, em aparelhos homologados pelo CONTRAN, permitam certificar seu estado.

\section{COMPLICADORES}

A tarefa (i.e., provar que determinada pessoa encontrava-se dirigindo sob a influência de álcool), que poderia parecer simples, torna-se complicada se levarmos em consideração os seguintes fatos:

1ํㅡㄹ Complicador: Princípio de Presunção de Inocência.

Nossa Carta Magna é expressa em afirmar que "ninguém será considerado culpado até o trânsito em julgado de sentença penal condenatória" (art. 5oㅡ. inc. LVII, CR/88).
O mesmo princípio fundamental encontra-se encartado no artigo XI, item 1, da Declaração Universal dos Direitos do Homem ${ }^{[2]}$ : "todo homem acusado de um ato delituoso tem o direito de ser presumido inocente até que a sua culpabilidade tenha sido provada de acordo com a lei, em julgamento público no qual Ihe tenham sido asseguradas todas as garantias necessárias à sua defesa" (p.24)

A prova da embriaguez, portanto, deverá ser convincente, séria e robusta suficiente para afastar um princípio previsto em nível constitucional.

Continuando em nossa tarefa, destaca-se um segundo complicador.

2ํ Complicador: o direito a não se autoincriminar.

Esse direito, que já poderia ser extraído do princípio de presunção de inocência, passou a integrar expressamente nosso ordenamento jurídico com a ratificação da Convenção Americana sobre Direitos Humanos, de 1969, também conhecida por Pacto de São José da Costa Rica ${ }^{[3]}$. Contempla o artigo $8^{\circ}$, item 2, alínea " $g$ ", o referido direito processual:

2. Toda pessoa acusada de delito tem direito a que se presuma sua inocência enquanto não se comprove legalmente sua culpa. Durante o processo, toda pessoa tem direito, em plena igualdade, às seguintes garantias mínimas:

\section{[...]}

g) direito de não ser obrigado a depor contra si mesma, nem a declarar-se culpada (p.75-6) ${ }^{9}$.

Bem ressaltou Scarance Fernandes ${ }^{18}$, da Faculdade de Direito da USP, que "Como derivação do direito a não se incriminar decorre o direito ao silêncio, consagrado expressamente para o preso no art. 5, LXIII, mas que a doutrina estendeu a todo indiciado que está sendo interrogado" (p.262).

Verifica-se, portanto, que a polêmica relacionada à "obrigatoriedade do teste do bafômetro", ou não, é grande.

Alguns Estados consideram os "testes de alcoolemia" de realização compulsória e tipificam a

\footnotetext{
* Cf. Decreto Regulamentar n. 24/98, que dispõe sobre "Exames de detecção de álcool ou de substâncias estupefacientes ou psicotrópicas na condução. **Declaração promulgada pela Assembléia Geral da Organização das Nações Unidas (ONU), em 10 de dezembro de 1948.

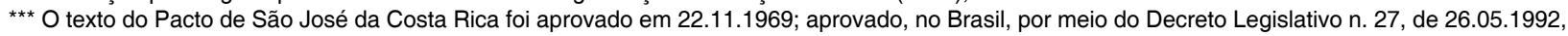
ratificado pela Carta de Adesão de 25.9.92, e incorporado por meio do Decreto n. 678, de 06.11.1992.
} 
recusa a esses exames técnicos como crime de desobediência (v.g., art. 158‥1. e art. 158‥3. do Código da Estrada, de Portugal, c.c. art. $348^{\circ} .1$., do Código Penal português; e art. 380, c.c. art. 556 do Código Penal de Espanha/1995).

\section{Portugal}

Código da Estrada - Art. 158‥1 - Devem submeter-se às provas estabelecidas para a deteç̧ão dos estados de influenciado pelo álcool ou por substâncias legalmente consideradas estupefacientes (entorpecentes, p.744) ${ }^{7}$ ou psicotrópicas:

a) Os condutores;

b) Os demais utentes da via pública, sempre que sejam intervenientes em acidente de trânsito.

Código Penal - Art. 348‥1. Quem faltar à obediência devida a ordem ou mandamento legítimos, regularmente comunicados e emanados de autoridade ou funcionário competente, é punido com pena de prisão de até 1 ano ou com pena de multa até 120 dias [...].

\section{Espanha (Código Penal / 1995)}

Art. 380. El conductor que, requerido por el agente de la autoridad, se negare a someterse a las pruebras legalmente estabelecidas para la comprobación de los hechos descritos en el artículo anterior, será castigado como autor de un delito de desobediencia grave, previsto en el artículo 556 de este Código.

Art. 556. Los que, sin estar compreendidos en el artículo 550, resistieren a la autoridad o sus agentes, o los desobecieren gravemente, en el ejercicio de sus funciones, serán castigados com la pena de prisión de seis meses a un año.

Outros Estados consideram a recusa aos exames como grave violação aos deveres impostos à manutenção do "privilégio para dirigir".

O Código de Trânsito do Estado da Pennsylvania (EUA), denominado Penn Code, impõe presunção legal de que o detentor de um privilégio de dirigir consente que seja submetido a um ou mais dos exames previstos em lei, tais como etilômetro, exame de urina ou de sangue ${ }^{12,13,16}$. Assim, os exames são obrigatórios para todo condutor que se envolver em acidente de trânsito com vítima, ou que se encontrar sob fundada suspeita de estar dirigindo sob influência de álcool ou substância entorpecente. Àquele que se recusar à realização dos exames poderá ser imposta penalidade de "suspensão da licença para dirigir", pelo prazo de 12 meses $^{[4] 12,13,16}$.

Diversamente, no Brasil (com o devido respeito aos doutrinadores que adotam entendimento diverso), o fato de recusar-se aos exames é considerado direito fundamental, garantido por lei (i.e., Tratado Internacional), e decorrente do princípio de presunção de inocência. Logo, o autor do fato, que está sendo acusado de dirigir sob a influência de álcool, não é obrigado a submeter-se ao exame do etilômetro (i.e., bafômetro) ou de coleta de material (sangue ou urina). O que aumenta o peso depositado sobre os demais meios de prova, em especial a prova testemunhal e o denominado exame clínico.

3 o Complicador: os equipamentos técnicos de aferição: etilômetros

\section{Como bem expuseram Carvalho e Leyton:}

Devido à grande extensão territorial brasileira e à escassez de laboratórios que executem dosagem alcoólica em amostras de sangue, o uso de etilômetros seria o método ideal para verificação da alcoolemia quanto ao cumprimento de nossa legislação. Por ser de baixo custo, de fácil operação e, principalmente, não-invasivo, tem sido amplamente utilizado em diversos países como método de triagem ou como teste comprobatório do uso de álcool.

No Brasil, os etilômetros são considerados "testes comprobatórios" e não apenas "testes de triagem"; ou seja, são meios de prova. No entanto, alguns cuidados tornam-se indispensáveis para que $o$ objeto da prova possa ser aceito em juízo e contribua para a formação do vencimento dos julgadores:

1) Correta operação do equipamento: atentar para a existência de "álcool residual remanescente na boca" (ideal: 15 a 20 min após a ingestão do "último gole"), e tantos outros. Fatos que exigem treinamento;

2) Necessidade de calibração (e manutenção) periódica, de acordo com as normas estabelecidas pelo fabricante;

3) Observar se os resultados são "expressos

${ }^{[4]}$ Cf. Penn Code, § 1547, (b). 
diretamente pelas concentrações de álcool no ar, ou indiretamente, pelas concentrações no sangue, havendo, nesse último caso, necessidade de se utilizar um "fator de conversão"[5];

4) Data de fabricação do aparelho para verificar se o resultado do exame teve em consideração o nível de 6 decigramas (art. 276) ou de 8 dg álcool por litro de sangue (Res. 737/89 - ora revogada), evitandose resultados confusos;

5) Aferição "por entidades indicadas pelo DENATRAN" (Res. 81/98, art. 5);

6) Homologação pelo CONTRAN (art. 277, CTB). Apenas equipamentos aprovados por órgãos técnicos (como o INMETRO) deveriam ser homologados;

8) Arquivo e registro das informações relacionadas ao aparelho. Assim, emitido um laudo e dado início ao processo administrativo ou instaurado o inquérito policial deveria ser juntada cópia da Homologação, Aferição, Calibração do equipamento 4 .

Todas essas cautelas são indispensáveis para assegurar a eficácia do equipamento e validade da prova produzida. Infelizmente não se tem conferido a devida atenção a esses aspectos, permitindo que dúvidas recaiam sobre o etilômetro, como meio de prova.

Retornando aos meios de prova admitidos em nossa legislação, verifica-se ainda a presença do exame clínico e da prova testemunhal.

\section{EXAME CLÍNICO}

É certo que o autor do fato não está obrigado a se auto-incriminar, e não poderá ser obrigado à realização do "teste do 'bafômetro"'. Nem por isso, poderá recusar-se a acompanhar as autoridades policiais, em caso de fundada suspeita de encontrarse dirigindo sob influência de álcool, à Delegacia de Polícia (para registro do fato) e aos estabelecimentos médicos (próprios ou hospitais locais) para realização de exame clínico.

O crime de desobediência pode caracterizar-se caso o condutor suspeito não se submeta a nenhum dos exames referidos no art. 277 do CTB, negando-se, inclusive, a acompanhar o agente da autoridade de trânsito aos locais de exame, em razão de ter-lhe sido dada uma ordem legal (p.145) ${ }^{10}$.

A noção do que se entende por exame clínico pode ser extraída do conceito de Penttila, citado por Souza ${ }^{19}$ : "um método pelo qual vários testes simples que descrevem a operação de várias funções psicomotoras são utilizados e os resultados dos testes são usados para tirar conclusões sobre o grau de intoxicação e usado com propósitos médico-legais e judiciais" (p.33).

Em relação aos testes que compõem o "exame clínico", dois merecem especial destaque: "sinal de Romberg" e "teste do Nistagmo".

O denominado "teste do Nistagmo" constitui "o mais importante dos sinais de intoxicação pelo álcool etílico" (p.65) ${ }^{10}$. Nistagmo consiste no "movimento involuntário do globo ocular quando existe um distúrbio vestibular ou do controle oculomotor" (p.65) ${ }^{10}$.

A aplicação do exame consiste no seguinte procedimento:

A aplicação do teste requer que o examinador possa ver os olhos do examinando, e que este possa ver o objeto a ser seguido com os olho. Nenhum aparelho especial é necessário para a realização do teste. Uma caneta, um lápis, uma pequena lanterna ou mesmo o dedo do examinador é suficiente. O examinando pode permanecer em pé ou sentado. Antes de realizar a prova, deve ser solicitado ao examinando que retire os óculos, se for o caso. Embora não seja necessário retirar lentes de contacto, deve-se ter em mente que estas podem cair durante o exame. Deve ser solicitado que o examinando siga com os olhos, sem mover a cabeça, o objeto (caneta, lápis, etc.), colocado a uns trinta centímetros da face do examinando. Cada olho deve ser examinado separadamente, devendo o examinador observar se o periciando segue com cada um dos olhos o objeto na mesma velocidade, assim como registrar a presença de anisocoria ${ }^{[6]}(\mathrm{p} .124)^{7}$, o que pode indicar cegueira em um dos olhos ou outros distúrbios neurológicos (p.68) ${ }^{19}$.

Como se percebe, trata-se de exame altamente técnico, que exige conhecimentos profissionais médicos e treinamento do perito-examinador.

[5] O Código da Estrada, de Portugal, contempla expressamente este "fator de conversão": "art. 81‥3. - Para efeitos de aplicação do disposto no presente Código, a conversão dos valores do teor de álcool no ar expirado (TAE) em teor de álcool no sangue (TAS) é baseada no princípio de que 1 mg de álcool por litro de ar expirado é equivalente a 2,3 g de álcool por litro de sangue."

${ }^{[6]}$ Anisocoria - "Diferença de diâmetro entre as duas pupilas". 
Há, no entanto, um segundo "teste", menos complexo e muito confiável, que tanto poderia ser aplicado pelos profissionais médicos, como pelos agentes de trânsito, no ato da fiscalização: o "teste de Romberg".

Apesar do nome difícil trata-se de exame altamente conhecido e divulgado pelos filmes norteamericanos. O risco é chegar-se em juízo, no momento da audiência para depor como testemunha, e afirmar que aplicou o "exame do quatro" ou determinou ao suspeito que "ficasse de quatro". O nome do exame é "Teste de Romberg", e consiste no seguinte procedimento: "o paciente fica em pé, com os pés juntos e os olhos fechados. Ocorre comumente um aumento das oscilações naqueles com disfunções do mecanismo cerebral ou vestibular" $(p .70)^{10}$.

Ao "teste de Romberg" poderiam ser associados os testes "dedo-dedo", "dedo-nariz" e "calcanhar joelho", formando o número quatro com as pernas. $O$ resultado do "teste de Romberg" leva em consideração "três graus de comprometimento":

1. suave balanço, centrado na região dos ombros;

2. balanço com eixo na região dos quadris;

3. queda (p.78) ${ }^{10}$.

A importância do "exame clínico" como meio de prova da embriaguez ao volante é inquestionável; principalmente em relação à influência de substâncias de efeitos análogos ao álcool, vez que os etilômetros não são capazes de detectar a presença dessas outras substâncias.

\section{PROVA TESTEMUNHAL}

A prova testemunhal é altamente relevante e muito bem aceita pelos Juízes de Direito e pelos Tribunais brasileiros:

"A embriaguez pode ser comprovada não apenas pelo exame de dosagem alcoólica que não é essencial, como também pela prova testemunhal. Esta última tem até preponderância sobre aquele exame, ante a relatividade dos efeitos do álcool sobre as pessoas" (TACRIM-SP - AC 311.583 - Rel. Dias Tatit) (p.440) ${ }^{8}$.

Aliás, já se chegou a afirmar que "No confronto das provas, a Jurisprudência Brasileira, não raras vezes, tem favorecido a prova testemunhal, desqualificando assim o exame químico" (p.25) ${ }^{10}$.

Em alguns aspectos, a prova testemunhal é imprescindível, em especial para provar a elementar "expondo a dano potencial a incolumidade de outrem"; por exemplo: a testemunha que viu, e confirma, que $o$ acusado dirigia o veículo em zigue-zague, passou pelo "sinal vermelho" e, por pouco, não atropelou um pedestre que se encontrava na estação de embarque e de desembarque de passageiros (também conhecida como "ponto de ônibus").

A prova testemunhal precisa ser séria, objetiva e, preferencialmente no caso de embriaguez ao volante, técnica, ou seja, prestada por policial ou agente de trânsito, que possa trazer informações precisas e dotadas de caráter técnico; evitando-se expressões ambiguas (como "fazer o quatro", que deve ser substituída pelo termo técnico: "teste de Romberg").

Recordo-me de uma instrução criminal em que o MM. Juiz de Direito perguntou à testemunha, que era Policial Militar, porque o condutor-infrator não foi preso, se os policiais estavam em dupla e o autor do fato estava embriagado? A resposta foi precisa: porque o condutor estava na "fase do Leão".

Em seguida, explicou o Policial Militar os diferentes estágios da embriaguez $(p .517)^{2}$ e as diferenças entre fases do leão, do macaco e do porco, que correspondem aos períodos da embriaguez alcoólica destacados por Simonin: (i) no primeiro período, ocorre excitação das funções intelectuais e estado de euforia; (ii) na segunda fase, perturbações psicosensoriais profundas geradoras de atos antisociais, autocrítica está abolida, surgem transtornos motores, e diminuição da força muscular; e (iii) na terceira fase, anestesia profunda com abolição dos reflexos, paralisia $(p .6-7)^{10}$.

Conhecimento (empírico ou científico), eis o fator que habilita ou desqualifica a testemunha como meio de prova e de convencimento do Julgador.

Importante lembrar, sempre, que a formação técnica e jurídica dos agentes de trânsito já se encontra consagrada no Egrégio Superior Tribunal de Justiça, tanto em relação aos documentos elaborados como a prova testemunhal:

EMENTA - Acidente de trânsito. Responsabilidade da empresa locadora. Boletim de ocorrência feito por policial rodoviário, o qual chegou poucos minu- 
tos após o evento. Precedentes. Súmula no 492 do Supremo Tribunal Federal.

1. O boletim de ocorrência feito por policial rodoviário federal, o qual chegou ao local minutos após o acidente, serve como elemento de convicção para o julgamento da causa, não se equiparando com aquele boletim decorrente de relato unilateral da parte.

2. A empresa locadora de veículos responde, civil e solidariamente com o locatário, pelos danos por este causados a terceiro, no uso do carro locado. (Súmula $n^{\circ} 492$, do Colendo Supremo Tribunal Federal).

3. Recurso especial não-conhecido (STJ, $3^{\text {a }}$ Turma, RESP 302.462/ES, Rel. Min. Carlos Alberto Menezes Direito, DJU de 04.02.2002, p. 351).

O que deve, então, a testemunha observar nos casos de Embriaguez ao Volante? Quais são os sinais de embriaguez?

Os professores Almeida Júnior e Costa Júnior apresentam um roteiro simples e interessante, de aspectos que podem ser observados pelas testemunhas (p.515) ${ }^{2}$ :

$1^{\circ}$ ) Aparência do indivíduo: sonolento? faces congestas? olhos vermelhos? suor? baba? soluços? vômito? desordem no vestuário?;

$2^{\circ}$ ) Atitude: ruidosa, excitada, exaltada, arrogante, loquaz, titubeante, deprimida, etc;

$3^{\circ}$ ) Orientação: sabe onde se encontra? que horas são?;

4º) Memória: ver se o indivíduo se lembra dos atos que praticou durante as últimas horas; se se lembra dos nomes de algumas ruas;

5) Faculdade de descrição: fazer o indivíduo descrever o fato que o trouxe ao exame; ou descrever uma gravura de revista que se lhe mostre;

6ํ) Prova de cálculo;

7º) Elocução: convidar o indivíduo a dizer algumas palavras de articulação difícil; a ler um trecho de jornal;

8) Andar: observar como caminha o indivíduo;

Sendo recomendável a aplicação do "teste de Romberg", à semelhança do exame clínico.

9) Coordenação motora: levantar um objeto do chão; colocar uma tampa na caneta, etc;

$10^{\circ}$ ) Escrita: escrever o nome, a idade, a profissão, o domicílio;
11) Pulso: irregularidade, rapidez; pupila: dimensões, reações à luz; sensibilidade dolorífica;

$12^{\circ}$ ) Hálito.

\section{CONCLUSÃO}

Tratamos, de forma resumida, porém científica, dos meios de prova da Embriaguez ao Volante, como instrumento de combate à impunidade. Durante a exposição, puderam ser identificados quatro pontos essenciais:

\section{Ciência}

$\left(1^{\circ}\right)$ destacar o caráter científico do Direito de Trânsito e ressaltar a necessidade de observarmos seus institutos sob a lente de validade imposta pela Constituição de uma sociedade que afirma ser um Estado Democrático de Direito;

\section{Fiscalização}

$\left(2^{\circ}\right)$ alertar aos profissionais de segurança pública, em especial os agentes de trânsito, a respeito da importância e do valor probatório dos documentos realizados nos locais de acidente, bem como a importância de seus depoimentos prestados em juízo (desde que prestados com a devida seriedade e conteúdo técnico). São fatores de convencimento inegáveis o peso do uniforme e do conhecimento técnico-profissional;

\section{Segurança}

(3) "os números encontrados neste estudo [ou seja, nas pesquisas científicas mencionadas] permitem que se recomende de forma enfática que os programas de prevenção sejam apoiados por uma fiscalização eficiente, com o uso ostensivo de etilômetros"11.

A inexistência de equipamentos técnicos de aferição não impede a apuração do fato; tampouco impede a apreciação da conduta pelo Poder Judiciário. A ausência de perícia, ou de exame pelo etilômetro, pode ser substituída pelo exame clínico e por prova testemunhal;

\section{Cidadania}

(4ํ) a todos os presentes à exposição (e ora leitores), procuramos identificar os instrumentos capazes de provar um fato em juízo; destacando a existência de alguns sinais característicos do estado de embriaguez. 
Isso porque todos os cidadãos podem ser chamados a prestar depoimento em juízo, na condição de testemunha; e estes sinais, observados e transmitidos pelas testemunhas, poderão servir de elementos de convencimento ao julgador.

Do exposto, e diante de tantos complicadores, se considerarmos de forma isolada cada um desses meios de prova (i.e., provas periciais, documentos e testemunhas) do cime de Embriaguez ao Volante, talvez tenhamos apenas meros indícios, incapazes de fundamentar a sentença condenatória e romper o princípio de presunção de inocência.

No entanto, se apresentados em um conjunto harmônico, dotado de seu indispensável caráter científico, certamente teremos elementos suficientes para que seja promovida Justiça, afastado-se o sentimento de impunidade que tem assolado esta grande Nação.

Honorato CM. Driving under influence of alcohol: how to prove the fact in judment and avoid the impunity? Saúde, Ética \& Justiça, São Paulo. 2003;8(1/2):35-43.

ABSTRACT: The present study emphasizes some technical and Scientifics aspects related to the crime of Driving Under Influence of Alcohol (described in article 306 of the Brazilian Road Traffic Act), emphasizing the means of proving in court accepted and the recognized importance of the clinical examination and the witnessing prove face Brazilian Justice.

KEY WORDS: Alcoholic intoxication. Alcohol drinking/legislation \& jurisprudence. Accidents, traffic.

\section{REFERÊNCIAS}

1. Abreu W. Código de trânsito brasileiro: infrações administrativas, crimes de trânsito e questões fundamentais. São Paulo: Saraiva; 1998.

2. Almeida Júnior A, Costa Júnior JBO. Lições de medicina legal. 20a ed. São Paulo: Ed. Nacional; 1991.

3. Amaral AS. Código da estrada anotado e comentado. 4a ed. Coimbra: Livraria Almedina; 2000.

4. Carvalho DG, Leyton W. Avaliação das concentrações de álcool no ar exalado: considerações gerais. Rev Psiquiatria Clín. 2000;27(2). Disponível em: http://www.hcnet.usp.br/ $\mathrm{ipq} / \mathrm{revista/r27(2)/art76.htm.}$

5. Dotti RA. Declaração universal dos direitos do homem e notas da legislação brasileira. 2a ed. Curitiba: J. M. Editora; 1999.

6. Ferrari $P$. Infortunistica stradale scientifica. Milano: Giuffrè; 1964.

7. Ferreira $A B H$. Dicionário da língua portuguesa. Rio de Janeiro: Nova Fronteira; 1985.

8. Franco AS, Stocco R, et al. Código penal e sua interpretação jurisprudencial. 6a ed. São Paulo: Editora Revista dos Tribunais; 1997. 3v.

9. Grinover AP, Scarance Fernandes A, Magalhães Gomes Filho A. As nulidades no processo penal. 6a ed. São Paulo: Editora Revista dos Tribunais; 1997.

10. Honorato CM. Trânsito: infrações e crimes. Campinas: Millennium Editora; 2000.

11. Leyton V, Greve JMD’A. Álcool em vítimas fatais de acidentes de trânsito no Estado de São Paulo, 1999. In: VI Congresso Nacional de Trânsito. São Paulo; 2001. CD-Rom.

12. Meyer MJ. Pennsylvania vehicle code annotated: law and commentary. 3rd ed. Philadelphia (PA): George T. Bisel Company; 1998.

13. Meyer MJ. Pennsylvania vehicle code annotated: law and commentary (amended through 746 A.2d). Supplement by Arthur S. Zanan. Philadelphia (PA): George T. Bisel Company; 2001.

14. New York (US). Driver's manual. New York: State Department of Motor Vehicles; 2001.

15. Paiva LC, Da Silva JA. Álcool e acidentes de trânsito. In: VI Congresso Nacional de Trânsito. São Paulo; 2001. CD-Rom.

16. Pennsylvania (US). Pennsylvania driver's manual. Pennsylvania: Department of Transportation Driver and Vehicle Service; 2001. (Pub. 95, 10/01).

17. Sagarna FA. Ley de tránsito. Serie de textos actualizados la ley com doctrina y jurisprudencia. Buenos Aires: La Ley; 1999.

18. Scarance Fernandes A. Processo penal constitucional. São Paulo: Editora Revista dos Tribunais; 1999.

19. Souza M. O exame clínico da embriaguez nas infrações de trânsito [dissertação]. São Paulo: Faculdade de Medicina da Universidade de São Paulo; 2001.

20. Touche F. L'art de bien conduire. Paris: Flammarion; 1954. 